\title{
Bronchodilator reversibility in asthma and COPD: findings from three large population studies
}

\author{
Christer Janson (10), ${ }^{1,2}$, Andrei Malinovschi ${ }^{3}$, Andre F.S. Amaral (1) ${ }^{2}$, \\ Simone Accordini ${ }^{4}$, Jean Bousquet ${ }^{5,6,7}$, A. Sonia Buist ${ }^{8}$, \\ Giorgio Walter Canonica9 , Barbro Dahlén ${ }^{10}$, Judith Garcia-Aymerich (1) 11,12,13, \\ Louisa Gnatiuc ${ }^{14}$, Marek L Kowalski ${ }^{15}$, Jaymini Patel ${ }^{2}$, Wan Tan ${ }^{16}$, Kjell Torén ${ }^{17}$, \\ Torsten Zuberbier ${ }^{7}$, Peter Burney ${ }^{2}$ and Deborah Jarvis ${ }^{2}$
}

@ERSpublications

Bronchodilator reversibility is at least as common in COPD as in asthma, indicating that measures of reversibility are of limited value for distinguishing asthma from COPD; however, bronchodilator reversibility in asthma may be a phenotypic marker. http://bit.ly/2W1oA4B

Cite this article as: Janson C, Malinovschi A, Amaral AFS, et al. Bronchodilator reversibility in asthma and COPD: findings from three large population studies. Eur Respir J 2019; 54: 1900561 [https://doi.org/ 10.1183/13993003.00561-2019].

ABSTRACT Bronchodilator response (BDR) testing is used as a diagnostic method in obstructive airway diseases. The aim of this investigation was to compare different methods for measuring BDR in participants with asthma and chronic obstructive pulmonary disease (COPD) and to study to the extent to which BDR was related to symptom burden and phenotypic characteristics.

Forced expiratory volume in $1 \mathrm{~s}(\mathrm{FEV} 1)$ and forced vital capacity (FVC) were measured before and $15 \mathrm{~min}$ after $200 \mu \mathrm{g}$ of salbutamol in 35628 subjects aged $\geqslant 16$ years from three large international population studies. The subjects were categorised in three groups: current asthma $(n=2833)$, COPD $(n=1146)$ and no airway disease $(n=31649)$. Three definitions for flow-related reversibility (increase in $\mathrm{FEV} 1$ ) and three for volume-related reversibility (increase in FVC) were used.

The prevalence of bronchodilator reversibility expressed as increase FEV $1 \geqslant 12 \%$ and $200 \mathrm{~mL}$ was $17.3 \%$ and $18.4 \%$ in participants with asthma and COPD, respectively, while the corresponding prevalence was $5.1 \%$ in those with no airway disease. In asthma, bronchodilator reversibility was associated with wheeze (OR 1.36, 95\% CI 1.04-1.79), atopy (OR 1.36, 95\% CI 1.04-1.79) and higher exhaled nitric oxide fraction, while in COPD neither flow- nor volume-related bronchodilator reversibility was associated with symptom burden, exacerbations or health status after adjusting for pre-bronchodilator FEV1.

Bronchodilator reversibility was at least as common in participants with COPD as those with asthma. This indicates that measures of reversibility are of limited value for distinguishing asthma from COPD in population studies. However, in asthma, bronchodilator reversibility may be a phenotypic marker. 


\section{Introduction}

Performing spirometry before and after inhalation of bronchodilators (bronchodilator response (BDR) testing) is used as an instrument for diagnosing asthma. In the Global Initiative for Asthma (GINA) report an increase of forced expiratory volume in $1 \mathrm{~s}(\mathrm{FEV} 1) \geqslant 12 \%$ and $200 \mathrm{~mL}$ from baseline after inhalation of a short-acting $\beta_{2}$-agonist is one of the recommended diagnostic criteria for asthma [1].

Bronchodilator reversibility is also common in chronic obstructive pulmonary disease (COPD) and $24 \%$ patients with moderate-to-severe COPD had an increase in FEV1 $(\geqslant 12 \%$ and $200 \mathrm{~mL})$ in the ECLIPSE study [2]. Several studies have indicated that bronchodilator reversibility may be an important phenotypic and prognostic marker in asthma [3-6]. However, it is less clear in COPD whether bronchodilator reversibility is related to any specific phenotypic characteristic or whether it is of prognostic value [2, 7-9]. BDR can also be measured as change in forced vital capacity (FVC), and there are data that indicate that in patients with severe airflow obstruction this volume-related bronchodilator reversibility could be more relevant than the flow-related bronchodilator reversibility measured by change in FEV1 [10].

There are many different ways of defining bronchodilator reversibility. Analyses from the Burden of Obstructive Lung Disease (BOLD) study have shown the 95th percentiles for BDR in healthy never-smokers to be $12.0 \%$ when expressed as increase in FEV1 as percentage of baseline [11], which fits well with clinical guidelines [1]. The corresponding value for FVC was $10.5 \%$. The threshold values for FEV1 and FVC were $10.0 \%$ and $9.2 \%$, respectively, when reversibility was expressed as percentage of the predicted value.

Most studies of bronchodilator reversibility have been based on patient cohorts or randomised controlled trials. In the present investigation we combined data from three large population studies: BOLD, European Community Respiratory Health Survey (ECRHS) III [12] and the Global Asthma and Allergy European Network $\left(\mathrm{GA}^{2} \mathrm{LEN}\right)$ [13]. These three studies used similar methodologies, covered a large age range and included many geographical regions. Findings obtained by combining these three studies would therefore have a high external validity.

The aim of this investigation was to compare different definitions of bronchodilator reversibility in participants with asthma and COPD in comparison with participants without these diseases. A secondary aim was to examine whether bronchodilator reversibility was related to symptom burden and phenotypic characteristics in asthma and COPD.

\section{Methodology}

This investigation includes 35628 subjects aged $\geqslant 16$ years from the three studies, who had performed a BDR test (figure 1, supplementary table E1).

In this analysis, the subjects were categorised into three groups. Current asthma was defined as self-reported physician-diagnosed asthma in combination with current use of asthmatic medication and/or asthma attack within the past 12 months in ECRHS III and GA ${ }^{2} L E N$ and as self-reported physician-diagnosed asthma in combination with the participant reporting still having asthma in BOLD. COPD was defined as having a post-bronchodilator FEV1/FVC ratio below the lower limit of normal in combination with a smoking history of $\geqslant 10$ pack-years and no history of ever having had asthma. No airway disease was defined as no history of ever having had asthma and not having COPD, according to the definition given here.

Subjects with a history of asthma but no current asthma were excluded from the main analyses, leaving 35628 in the analysis (figure 1). However, in a separate analysis we studied reversibility in participants

Affiliations: ${ }^{1}$ Dept of Medical Sciences, Respiratory Allergy and Sleep Research, Uppsala University, Uppsala, Sweden. ${ }^{2}$ Population Health and Occupational Disease, National Heart and Lung Institute, Imperial College London, London, UK. ${ }^{3}$ Dept of Medical Sciences, Clinical Physiology, Uppsala University, Uppsala, Sweden.

${ }^{4}$ Unit of Epidemiology and Medical Statistics, Dept of Diagnostics and Public Health, University of Verona, Verona, Italy. ${ }^{5}$ Fondation FMC VIA-LR, Montpellier, France. ${ }^{6}$ Euforea, Brussels, Belgium. ${ }^{7}$ Allergy Centre Charité, Dept of Dermatology and Allergy, Charité Universitätsmedizin Berlin, Berlin, Germany. ${ }^{8}$ Pulmonary and Critical Care Medicine, Oregon Health and Science University, Portland, OR, USA. ${ }^{9}$ Personalized Medicine Clinic Asthma and Allergy Humanitas Research Hospital, Milan, Italy. ${ }^{10}$ Dept of Medicine, Unit for Heart and Lung disease, Karolinska Institutet, Stockholm, Sweden. ${ }^{11}$ ISGlobal, Barcelona, Spain. ${ }^{12}$ Universitat Pompeu Fabra (UPF), Barcelona, Spain. ${ }^{13}$ CIBER Epidemiología y Salud Pública (CIBERESP), Barcelona, Spain. ${ }^{14}$ Clinical Trial Service Unit and Epidemiological Studies Unit, Nuffield Dept of Population Health, University of Oxford, Oxford, UK. ${ }^{15}$ Dept of Immunology and Allergy, Medical University of Lodz, Lodz, Poland. ${ }^{16}$ Centre for Heart Lung Innovation (Tan, Sin), University of British Columbia, St. Paul's Hospital Vancouver, Vancouver, BC, Canada. ${ }^{17}$ Dept of Occupational and Environmental Medicine, University of Gothenburg, Gothenburg, Sweden.

Correspondence: Christer Janson, Dept of Respiratory Medicine, Uppsala University, Akademiska sjukhuset, Uppsala, SE 751 85, Sweden. E-mail: christer.jansonamedsci.uu.se 


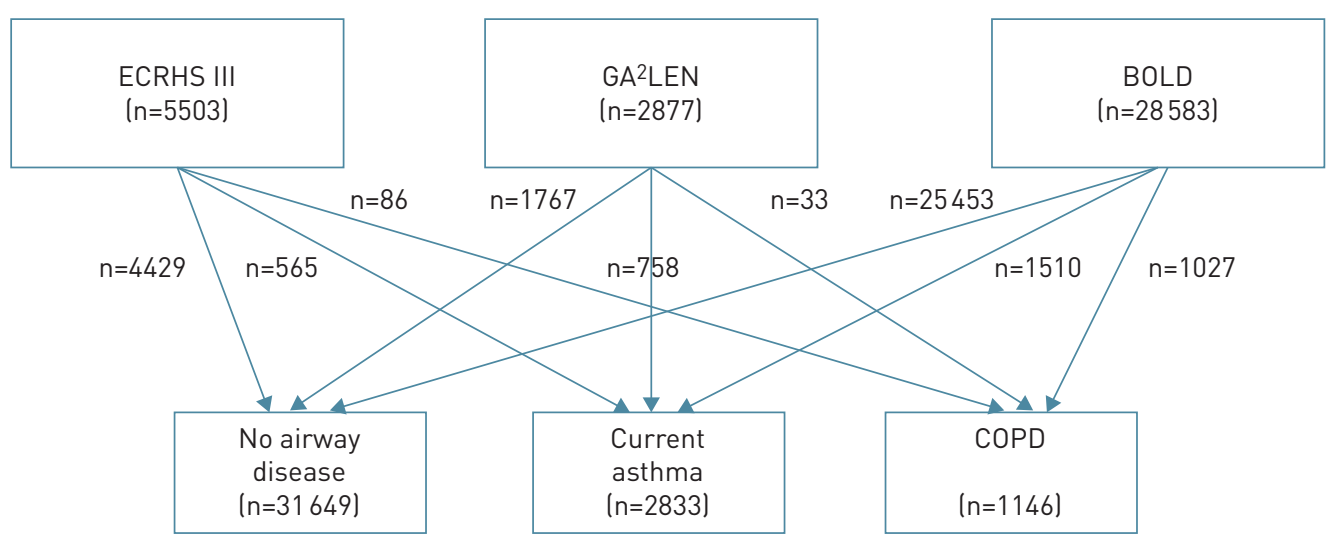

FIGURE 1 Study design. ECRHS: European Community Respiratory Health Survey; GA ${ }^{2}$ LEN: Global Asthma and Allergy European Network; BOLD: Burden of Obstructive Lung Disease study; COPD: chronic obstructive pulmonary disease.

with asthma-COPD overlap, which in this investigation was defined as having a history of doctor-diagnosed asthma and a post-bronchodilator FEV1/FVC below the lower limit of normal in combination with a smoking history of $\geqslant 10$ pack-years.

\section{Spirometry and bronchodilator reversibility test}

Lung function data were obtained in all subjects using the ndd EasyOne Spirometer (ndd Medizintechnik AG, Zurich, Switzerland). Lung function was measured before and $15 \mathrm{~min}$ after administration of $200 \mu \mathrm{g}$ salbutamol via metered dose inhaler with spacer. Prediction equations derived from the Global Lung Initiative were used to compute predicted FEV1 and FVC [14]. Weight and height were measured at the clinic visit and body mass index (BMI) was calculated (weight $\left.(\mathrm{kg}) /(\text { height }(\mathrm{m}))^{2}\right)$.

The participants were asked to refrain from using short-acting $\beta_{2}$-agonists for $\geqslant 6 \mathrm{~h}$, long-acting $\beta_{2}$-agonists for $12 \mathrm{~h}$ and long-acting antimuscarinic agents for $24 \mathrm{~h}$ before performing the spirometry. The spirometry was rescheduled if the participant had had a respiratory infection within the previous 4 weeks.

This study included both flow-related bronchodilator reversibility, defined by change in FEV1, and volume-related bronchodilator reversibility, defined by change in FVC.

\section{Flow-related bronchodilator reversibility}

Flow-related bronchodilator reversibility was defined as change in $\mathrm{FEV}_{1} \geqslant 12 \%$ of the baseline values, change in $\mathrm{FEV}_{1} \geqslant 10 \%$ predicted [11] and change in $\mathrm{FEV}_{1} \geqslant 12 \%$ of the baseline values in combination with increase in absolute volume $\geqslant 200 \mathrm{~mL}[1]$.

\section{Volume-related bronchodilator reversibility}

Volume-related bronchodilator reversibility was defined as change in FVC $\geqslant 10.5 \%$ of the baseline values; change in FVC $\geqslant 9.2 \%$ pred [11] and change in FVC $\geqslant 10.5 \%$ of the baseline values in combination with increase in absolute volume $\geqslant 320 \mathrm{~mL}$ [11].

\section{Assessment in participants with current asthma}

The association between bronchodilator reversibility and the following variables was assed: wheeze, wheeze in combination with breathlessness, wheeze when not having a cold, nocturnal chest tightness, attacks of breathlessness at rest and following activity and attacks of nocturnal cough in the past 12 months, as well as habitual cough (usually coughing in the morning or during daytime) and chronic bronchitis (bringing up phlegm $\geqslant 3$ months per year), number of attacks of asthma in the past 3 months and nasal allergy.

Smoking history was categorised as current, ex- and never-smoker.

Information on allergic sensitisation was obtained through skin-prick testing. The following allergens were included: Dermatophagoides pteronyssinus, Dermatophagoides farinae, timothy grass, ragweed, cat, Cladosporium herbarum, Alternaria tenuis, Parietaria, cockroach, olive and birch. These data were not available in the BOLD study. 
Measurement of exhaled nitric oxide fraction ( $F \mathrm{eNO}$ ) was performed using the NIOX MINO (Aerocrine, Stockholm, Sweden). These data were only available from the ECRHS III and the Swedish centres in the GA ${ }^{2}$ LEN study [15].

\section{Assessment in participants with COPD}

The association between bronchodilator reversibility and the following variables was assessed: wheeze, wheeze in combination with breathlessness, wheeze when not having a cold, in the past 12 months, habitual cough (usually coughing in the morning or during daytime) and chronic bronchitis (bringing up phlegm $\geqslant 3$ months per year), and dyspnoea assessed using the modified Medical Research Council scale and exacerbations (having breathing problems that got so bad that the subject had to see a healthcare provider or was hospitalised).

Smoking history was categorised as ex-smokers and current smokers.

Health status was assessed by the 12-item short form (SF-12) questionnaire (version 2). The physical and mental health component scores were calculated, with higher values indicating better health status [16]. This information was only available from the BOLD study.

\section{Statistical analyses}

The prevalence of bronchodilator reversibility in the three groups of participants was calculated. Differences between the groups was assessed using the Chi-squared test and, in order to adjust for pre-bronchodilator $\mathrm{FEV}_{1}$, multiple logistic regression. The Chi-squared test and multivariable logistic regression was used when analysing the association between bronchodilator reversibility and symptom and phenotypic characteristics in the participants with asthma and COPD with and without BDR in the asthma and COPD groups. In the multivariable models adjustment was made for age, sex, smoking history, pre-bronchodilator FEV1 and study.

\section{Sensitivity analyses}

Sensitivity analyses were performed to test whether the associations differed between the studies. The association of bronchodilator reversibility in participants with current asthma using only participants from ECRHS III and GA ${ }^{2}$ LEN and the association to bronchodilator reversibility in COPD only using the BOLD study were assessed. Analyses were also performed after adjusting for use of inhaled corticosteroids.

\section{Results}

The investigation included 16776 males and 18852 females, mean \pm sD age $54.1 \pm 11.0$ years (range 1698 years). There were large differences across the study groups in regard to age, sex distribution, smoking history, BMI and lung function (table 1).

The prevalence of bronchodilator reversibility in subjects with no airway disease, asthma and COPD is presented in table 1 . The prevalence of BDR was significantly higher in the asthma and COPD group compared to the group without airway disease. The prevalence of bronchodilator reversibility was higher for COPD than for asthma for most of the different definitions of bronchodilator reversibility used in the analyses. The same pattern was seen when analysing only the ECRHS and GA ${ }^{2}$ LEN populations and only the BOLD survey (supplementary tables E2 and E3).

The association between bronchodilator reversibility and having asthma or COPD compared to those with no airway disease remained significant after adjustment for pre-bronchodilator FEV1, but the association became stronger for asthma than COPD for all the flow-related responsiveness variables, while no significant difference was found for the volume-related bronchodilator reversibility definitions between asthma and COPD (figure 2). The absolute increase in FEV1 was higher in the group with asthma with flow-related bronchodilator reversibility (increase in FEV1 $>12 \%$ of baselines) than in the corresponding group with COPD (358 versus $295 \mathrm{~mL}, \mathrm{p}<0.0001$ ). No significant difference in absolute increase in FVC was found between the asthma and COPD groups in those with volume-related bronchodilator reversibility (increase in $\mathrm{FVC}>10.5 \%$ of baselines) (500 versus $533 \mathrm{~mL}, \mathrm{p}=0.09$ ).

\section{Current asthma}

Participants with asthma that had bronchodilator reversibility had a higher prevalence of most symptoms and higher FeNO levels than those with asthma without bronchodilator reversibility. Participants with asthma and flow-related bronchodilator reversibility were more often sensitised to mites and had a higher total IgE than participants with asthma without flow-related bronchodilator reversibility (table 2).

Wheeze, allergic sensitisation and higher FeNO were independently associated with flow-related bronchodilator reversibility after adjustment for pre-bronchodilator FEV1, age, BMI, smoking history and 
TABLE 1 Characteristics and prevalence of bronchodilator reversibility

\begin{tabular}{|c|c|c|c|c|c|c|}
\hline & $\begin{array}{l}\text { No airway disease } \\
\text { (controls) }\end{array}$ & $\begin{array}{l}\text { Current } \\
\text { asthma }\end{array}$ & $\begin{array}{l}\text { p-value versus } \\
\text { controls }\end{array}$ & COPD & $\begin{array}{l}\text { p-value versus } \\
\text { controls }\end{array}$ & $\begin{array}{l}\mathrm{p} \text {-value asthma } \\
\text { versus COPD }\end{array}$ \\
\hline Subjects n & 31649 & 2833 & & 1146 & & \\
\hline Female & 53.0 & 63.1 & $<0.0001$ & 26.4 & $<0.0001$ & $<0.0001$ \\
\hline Age years & $54 \pm 11$ & $53 \pm 12$ & $<0.0001$ & $60 \pm 11$ & $<0.0001$ & $<0.0001$ \\
\hline Smoking history & & & $<0.0001$ & & $<0.0001$ & $<0.0001$ \\
\hline Current smoker & 17.0 & 15.1 & & 59.1 & & \\
\hline $\mathrm{BMI} \mathrm{kg} \cdot \mathrm{m}^{-2}$ & & & $<0.0001$ & & $<0.0001$ & $<0.0001$ \\
\hline$<20$ & 8.3 & 5.3 & & 14.8 & & \\
\hline $20-25$ & 33.6 & 29.6 & & 37.4 & & \\
\hline$>25-30$ & 35.3 & 32.2 & & 32.8 & & \\
\hline$>30$ & 22.8 & 32.9 & & 15.0 & & \\
\hline Post-bronchodilator $\mathrm{FEV}_{1} / \mathrm{FVC} \%$ & $79 \pm 7$ & $73 \pm 12$ & $<0.0001$ & $58 \pm 9$ & $<0.0001$ & $<0.0001$ \\
\hline \multicolumn{7}{|l|}{ Flow response } \\
\hline$\Delta \mathrm{FEV} 1 \geqslant 12 \%$ from baseline & 5.9 & 20.2 & $<0.0001$ & 24.5 & $<0.0001$ & $<0.0001$ \\
\hline$\Delta \mathrm{FEV}_{1} \geqslant 10 \%$ pred & 8.9 & 25.8 & $<0.0001$ & 29.8 & $<0.0001$ & 0.10 \\
\hline$\Delta \mathrm{FEV} 1 \geqslant 12 \%$ and $200 \mathrm{~mL}$ from baseline & 5.1 & 17.3 & $<0.0001$ & 18.4 & $<0.0001$ & 0.39 \\
\hline \multicolumn{7}{|l|}{ Volume response } \\
\hline$\Delta \mathrm{FVC} \geqslant 10.5 \%$ from baseline & 5.3 & 15.8 & $<0.0001$ & 25.2 & $<0.0001$ & $<0.0001$ \\
\hline$\Delta \mathrm{FVC} \geqslant 9.2 \%$ pred & 10.7 & 22.8 & $<0.0001$ & 31.6 & $<0.0001$ & $<0.0001$ \\
\hline$\Delta \mathrm{FVC} \geqslant 10.5 \%$ and $320 \mathrm{~mL}$ from baseline & 3.6 & 11.8 & $<0.0001$ & 21.6 & $<0.0001$ & $<0.0001$ \\
\hline
\end{tabular}

Data are presented as $\%$ or mean \pm SD, unless otherwise stated. COPD: chronic obstructive pulmonary disease; BMI: body mass index; FEV1: forced expiratory volume in $1 \mathrm{~s}$; FVC: forced vital capacity.

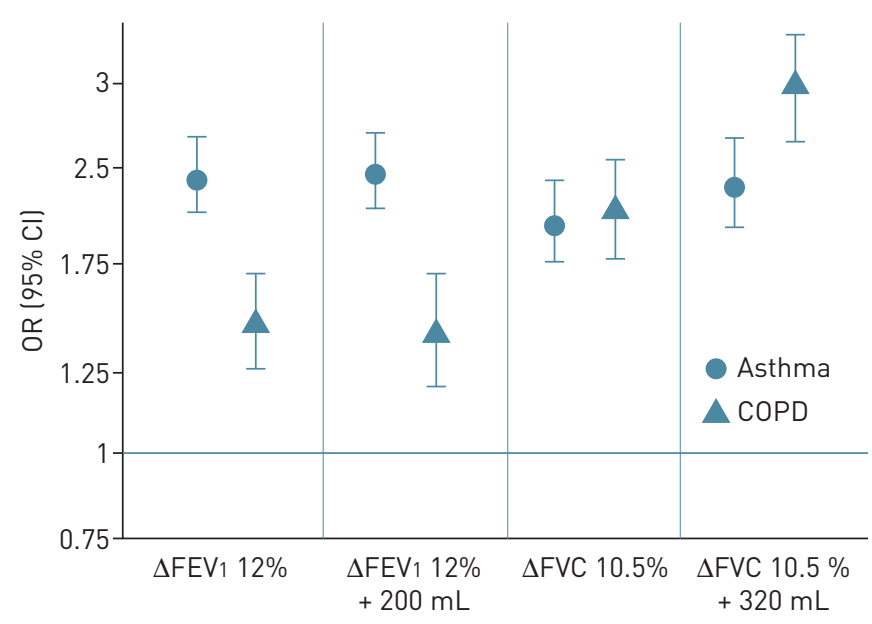

FIGURE 2 Association between bronchodilator responsiveness and asthma and chronic obstructive pulmonary disease (COPD) with participants without airway disease as the reference group. The association is expressed as OR (95\% CI) adjusted for pre-bronchodilator forced expiratory volume in $1 \mathrm{~s}$ (FEV1). FVC: forced vital capacity. 
TABLE 2 Comparison between participants with asthma with or without bronchodilator reversibility

\begin{tabular}{|c|c|c|c|c|c|c|}
\hline & \multicolumn{3}{|c|}{$\Delta \mathrm{FEV} 1$} & \multicolumn{3}{|c|}{$\Delta \mathrm{FVC}$} \\
\hline & $<12 \%$ & $\geqslant 12 \%$ & p-value & $<10.5 \%$ & $\geqslant 10.5 \%$ & p-value \\
\hline Subjects n & 2261 & 572 & & 2280 & 429 & \\
\hline Wheeze and breathlessness & 55.1 & 63.9 & $<0.0001$ & 55.8 & 62.7 & 0.008 \\
\hline Wheeze when no cold & 44.4 & 47.5 & 0.18 & 44.8 & 49.0 & 0.12 \\
\hline Nocturnal chest tightness ${ }^{\#}$ & 41.2 & 51.0 & 0.10 & 40.4 & 57.0 & $<0.0001$ \\
\hline Nocturnal breathlessness ${ }^{\#}$ & 26.6 & 36.2 & 0.006 & 26.6 & 36.3 & 0.02 \\
\hline Nocturnal cough ${ }^{\#}$ & 55.5 & 51.0 & 0.24 & 55.8 & 47.1 & 0.052 \\
\hline Habitual cough & 49.0 & 47.0 & 0.39 & 47.7 & 50.4 & 0.31 \\
\hline Chronic bronchitis & 23.9 & 29.6 & 0.006 & 22.4 & 34.5 & $<0.0001$ \\
\hline Asthma attacks in past 3 months & & & 0.99 & & & 0.96 \\
\hline 0 & 61.9 & 62.0 & & 62.0 & 61.6 & \\
\hline \multicolumn{7}{|l|}{ IgE sensitisation" } \\
\hline Pets & 51.0 & 58.0 & 0.09 & 52.7 & 50.4 & 0.63 \\
\hline Mite & 33.9 & 42.4 & 0.03 & 35.3 & 35.8 & 0.91 \\
\hline Pollen & 54.6 & 56.0 & 0.74 & 56.0 & 50.4 & 0.24 \\
\hline Any & 70.1 & 75.1 & 0.18 & 72.3 & 67.0 & 0.22 \\
\hline Total lgE & $64(59-71)$ & $108(90-131)$ & $<0.0001$ & $68(62-74)$ & 80 (59-108) & 0.28 \\
\hline $\mathrm{FeNO}^{+}$ & $20(19-21)$ & $25(22-29)$ & 0.001 & $20(19-21)$ & $24(20-28)$ & 0.04 \\
\hline
\end{tabular}

Data are presented as $\%$ or geometric mean $(95 \% \mathrm{Cl})$, unless otherwise stated. FEV1: forced expiratory volume in $1 \mathrm{~s}$; FVC: forced vital capacity; FeNO: exhaled nitric oxide fraction. ${ }^{\#}: \mathrm{n}=1321 ;{ }^{\text {ๆ }} \mathrm{n}=1215{ }^{+}{ }^{+}$: $\mathrm{n}=878$.

study (table 3). Having habitual cough was negatively associated with flow-related BDR. Having nocturnal chest tightness, not having nocturnal cough and higher FeNO was independently associated with volume-related bronchodilator reversibility (table 3). Younger age and having a BMI $<20 \mathrm{~kg} \cdot \mathrm{m}^{-2}$ was independently associated with flow-related bronchodilator reversibility, while higher age and male sex was related to volume-related bronchodilator reversibility. Having flow-related bronchodilator reversibility (increase in $\mathrm{FEV}_{1}>12 \%$ of baseline) was independently associated with having a $F_{\text {eNO }} \geqslant 25 \mathrm{ppb}$ (OR 2.36, 95\% CI 1.45-3.83) and allergic sensitisation (OR 2.08, 95\% CI 1.34-3.24).

\section{COPD}

The prevalence of bronchodilator reversibility increased with the severity of the airway obstruction. The prevalence of bronchodilator reversibility (expressed as change in FEV1 $>12 \%$ of baseline) was $12.0 \%$, $27.2 \%$ and $39.3 \%$ in those with a post-bronchodilator $\mathrm{FEV}_{1}>80 \%, 80-50 \%$ and $<50 \%$ pred, respectively $(\mathrm{p}<0.0001)$. Participants with COPD and bronchodilator reversibility reported more symptoms, more exacerbations, more dyspnoea and lower quality of life in the physical domain than participants with COPD and no bronchodilator reversibility (table 4). However, all these associations became statistically nonsignificant after adjusting for pre-bronchodilator FEV1, age, BMI, smoking history and study (table 5). The only exception was a significant independent association between reported wheezing when not having a cold and having the combination of an increase in FEV1 $\geqslant 12 \%$ and $200 \mathrm{~mL}$. Female sex and higher age were independently associated with having an increase in FVC $\geqslant 10.5 \%$.

There was no difference in the association between bronchodilator reversibility and the independent variables when bronchodilator reversibility was defined from BDR expressed as percentage of predicted instead of percentage of baseline (supplementary tables E4 and E5).

\section{Asthma-COPD overlap}

The number of participants with asthma-COPD overlap was 315. The prevalence of flow-related reversibility measured as an increase in $\mathrm{FEV}_{1} \geqslant 12 \%$ was $33.6 \%$, while the prevalence of volume-related reversibility expressed as an increase in $\mathrm{FVC} \geqslant 10.5 \%$ was $36.8 \%$. Reversibility was related to lower pre-bronchodilatory FEV1 and FVC $(<0.0001)$, but not to any of the clinical and phenotypic variables described earlier (data not shown). 
TABLE 3 Determinants of bronchodilator reversibility in subjects with asthma

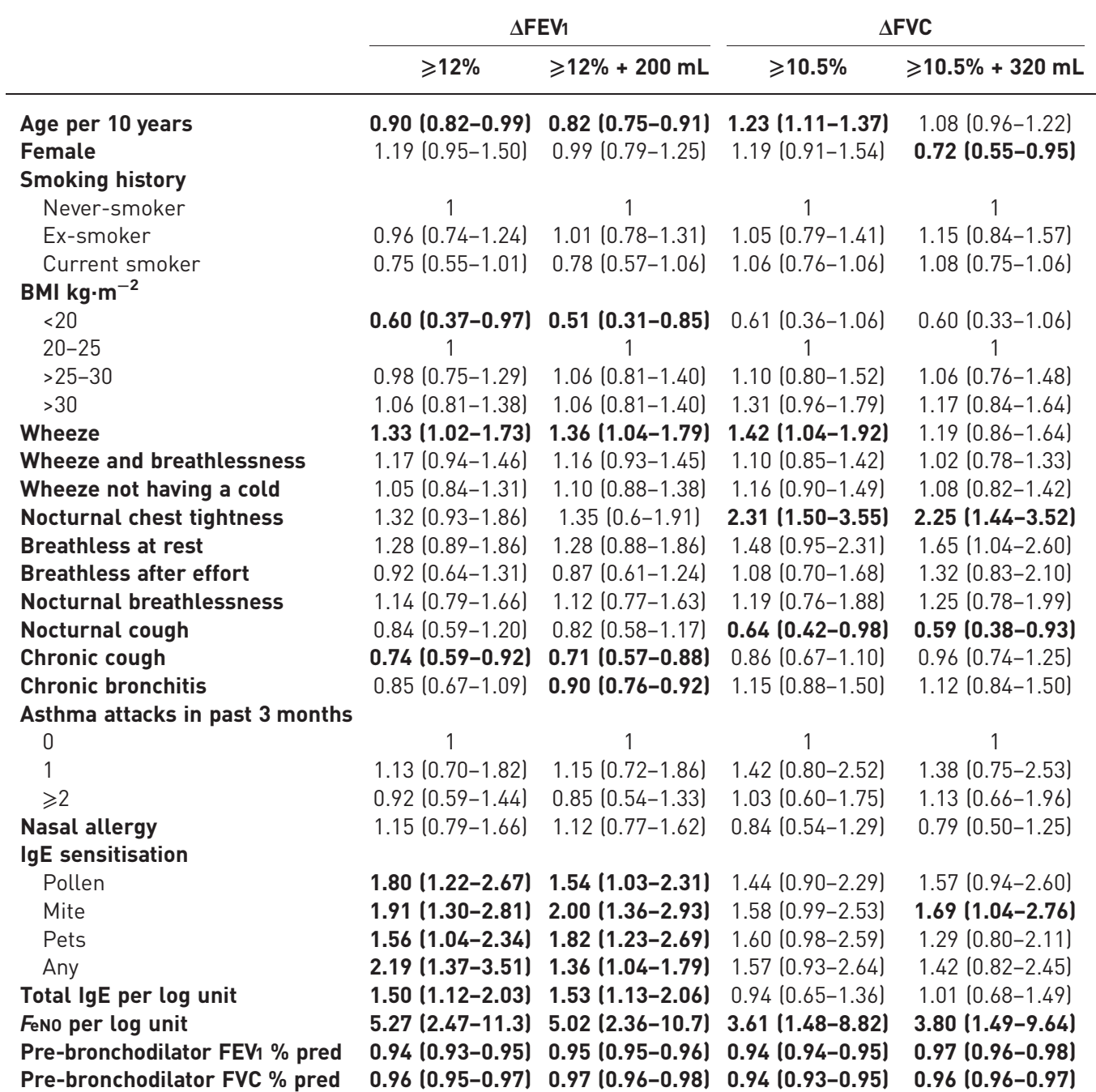

Data are presented as OR $(95 \% \mathrm{CI})$, adjusted by sex, age, body mass index (BMI), smoking, pre-bronchodilator forced expiratory volume in $1 \mathrm{~s}\left(\mathrm{FEV}_{1}\right)$ and study. Statistically significant associations are presented in bold. FVC: forced vital capacity; FeNO: exhaled nitric oxide fraction.

\section{Sensitivity analyses}

The results remained largely similar when only analysing association with bronchodilator reversibility in participants with current asthma using the ECRHS III and GA ${ }^{2}$ LEN study and analysing association with bronchodilator reversibility in COPD only using the BOLD study. Adjusting for use of inhaled corticosteroids did not change the results.

\section{Discussion}

The main findings of the investigation were that both flow- and volume-related bronchodilator reversibility was at least as common in participants with smoking-related COPD as those with current asthma. Among participants with current asthma, bronchodilator reversibility was independently associated with having wheeze, atopic sensitisation and higher FeNO. Among those with COPD, reversibility was associated with more symptoms and lower health status, but these association became statistically nonsignificant after adjusting for pre-bronchodilator FEV1.

To our knowledge, this analysis is the largest study ever to examine clinical correlates of bronchodilator reversibility. We show that $17 \%$ of those with asthma and $18 \%$ of those with COPD had an increase of FEV1 of $\geqslant 12 \%$ and $\geqslant 200 \mathrm{~mL}$ after bronchodilation. This accords with previous studies showing that bronchodilator testing is not useful for distinguishing between asthma and COPD [17]. Previous work 


\begin{tabular}{|c|c|c|c|c|c|c|}
\hline & \multicolumn{3}{|c|}{$\Delta \mathrm{FEV} 1$} & \multicolumn{3}{|c|}{$\Delta \mathrm{FVC}$} \\
\hline & $<12 \%$ & $\geqslant 12 \%$ & p-value & $<10.5 \%$ & $\geqslant 10.5 \%$ & p-value \\
\hline Subjects $\mathrm{n}$ & 865 & 281 & & 833 & 280 & \\
\hline Wheeze & 37.3 & 52.0 & $<0.0001$ & 40.2 & 45.0 & 0.16 \\
\hline Wheeze and breathlessness & 15.3 & 30.6 & $<0.0001$ & 17.2 & 25.7 & 0.002 \\
\hline Wheeze when no cold & 17.2 & 28.8 & $<0.0001$ & 18.8 & 24.3 & 0.047 \\
\hline Habitual coughing & 39.3 & 47.0 & 0.02 & 40.6 & 44.3 & 0.28 \\
\hline Chronic bronchitis & 18.7 & 26.2 & 0.007 & 18.8 & 26.3 & 0.008 \\
\hline Exacerbations & & & 0.008 & & & 0.13 \\
\hline 0 & 94.9 & 89.6 & & 94.3 & 91.0 & \\
\hline 1 & 1.4 & 2.3 & & 1.3 & 2.8 & \\
\hline$\geqslant 2$ & 3.7 & 8.1 & & 4.5 & 6.3 & \\
\hline mMRC score & & & $<0.0001$ & & & 0.001 \\
\hline 0 & 60.4 & 43.5 & & 58.9 & 46.2 & \\
\hline 1 & 24.6 & 31.3 & & 25.8 & 29.4 & \\
\hline 2 & 4.3 & 4.9 & & 4.4 & 5.5 & \\
\hline 3 or 4 & 10.6 & 20.3 & & 10.9 & 18.9 & \\
\hline \multicolumn{7}{|l|}{ SF-12\# } \\
\hline MCS-12 & $50.5 \pm 10.2$ & $49.2 \pm 11.0$ & 0.12 & $50.5 \pm 10.0$ & $49.6 \pm 11.3$ & 0.32 \\
\hline PCS-12 & $45.1 \pm 10.2$ & $42.2 \pm 11.0$ & 0.0006 & $45.0 \pm 10.2$ & $42.6 \pm 11.1$ & 0.005 \\
\hline
\end{tabular}

Data are presented as \% or mean \pm SD, unless otherwise stated. FEV1: forced expiratory volume in $1 \mathrm{~s} ; \mathrm{FVC}$ : forced vital capacity; mMRC: modified Medical Research Council; SF-12: 12-item short form questionnaire; MCS: mental health component score; PCS: physical component score. ${ }^{\#}: \mathrm{n}=839$.

shows that only a minority of patients with asthma have BDR [18-20] and the prevalence of bronchodilator reversibility for COPD in our study is fairly well in line with what was found in the ECLIPSE study, where the corresponding prevalence was 24\% [2]. Bronchodilator reversibility was strongly related to pre-bronchodilator lung function. When adjusting for pre-bronchodilator FEV1, flow-related bronchodilator reversibility was more strongly associated with asthma than COPD, whereas no significant difference in volume-related bronchodilator reversibility was found between asthma and COPD.

We found that bronchodilator reversibility was independently associated with IgE sensitisation and higher FeNO levels in the group with asthma, suggesting that measuring BDR might be of value for phenotypic characterisation of patients with asthma. Higher FeNO levels is a marker of type 2 inflammation, frequently used as an indicator of responsiveness to inhaled corticosteroids [21]. Our findings are in accordance with one study in asthma that found that bronchodilator reversibility was associated with being more responsive to inhaled corticosteroids [6]. In addition, studies have reported that patients with asthma with bronchodilator reversibility are more likely to have difficult-to-control asthma [3-5]. In the present study, we found no association between reported attacks of asthma in the past 3 months and bronchodilator reversibility, but BDR was associated with having wheeze, suggesting a relationship with less well controlled asthma.

In the unadjusted analyses, COPD patients with bronchodilator reversibility had a higher prevalence of wheeze, dyspnoea, exacerbations and lower health status. However, this association is largely related to both reversibility and symptoms being more common in those with low lung function Almost all of these associations became statistically nonsignificant after adjusting for pre-bronchodilator FEV1. This has been seen in several other studies showing no association between bronchodilator reversibility and prognosis in COPD when baseline lung function is taken into account $[2,7-9]$. However, there are some exceptions. In one analysis of ECLIPSE, COPD patients with bronchodilator reversibility had a faster decline in FEV 1 [22]; in a large Spanish study, higher reversibility was associated with lower risk of hospitalisation [23]; and in another study bronchodilator reversibility was weakly but statically significantly associated with sputum eosinophil count in COPD [24].

In the present study there was no difference between COPD with and without bronchitis, COPD with and without frequent exacerbations or COPD patient that were ex-smokers or current smokers in the adjusted analyses. However, apart from this we have no phenotypic information on the participants with COPD.

Bronchodilator reversibility is usually defined based on the relative change in FEV1 from the baseline value. An alternative way is to measure BDR as a change expressed as percentage of predicted value, which potentially decreases the influence of baseline lung function $[10,25]$. However, we show that both 
TABLE 5 Determinants of bronchodilator reversibility in subjects with chronic obstructive pulmonary disease

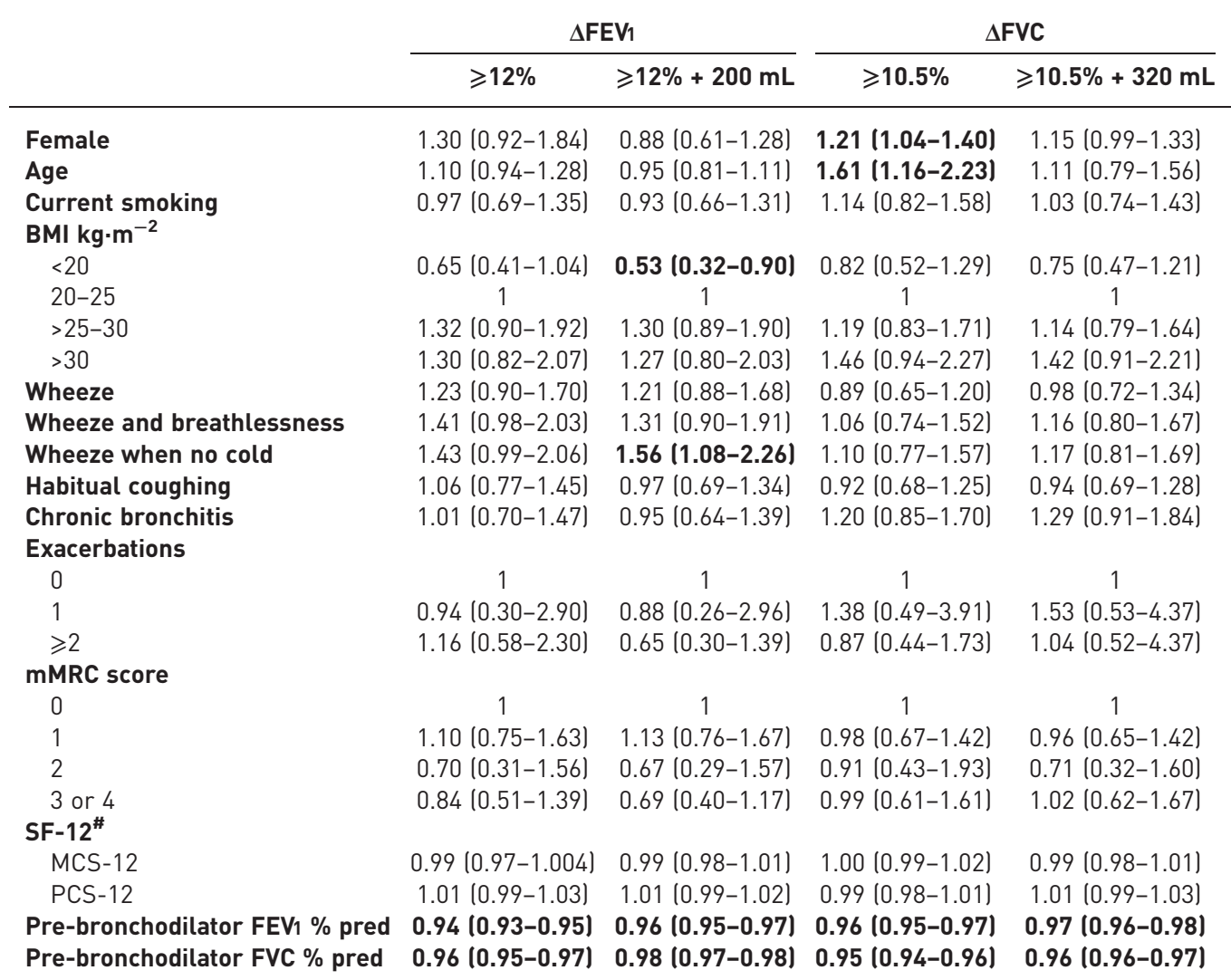

Data are presented as OR $(95 \%$ CI), adjusted by sex, age, body mass index (BMI), smoking, pre-bronchodilator forced expiratory volume in $1 \mathrm{~s}\left(\mathrm{FEV}_{1}\right)$ and study. Statistically significant associations are presented in bold. FVC: forced vital capacity; mMRC: modified Medical Research Council; SF-12: 12-item short form questionnaire; MCS: mental health component score; PCS: physical component score.

measures are highly dependent on pre-bronchodilator lung function. Moreover, there was no difference in the association between bronchodilator reversibility with symptoms and phenotypic characteristics in the asthma group between the two methods.

Volume-related bronchodilator reversibility was more common in COPD than asthma. This was also found after adjusting for pre-bronchodilator FEV1. QUANJER et al. [10] found that the bronchodilator response to FVC increased with the level of airflow obstruction. They suggested that volume-related response may be more clinically relevant than increase in FEV1 in patients with severe airflow obstruction. However, in the present study, neither flow-related nor volume-related bronchodilator reversibility were independently associated with symptom burden, health status or dyspnoea in the COPD population.

The study has a high external validity as it is based on participants from the general population from different parts of the world. The method for testing BDR and assessment of symptoms was similar in all three studies, but there are limitations that should be taken into account. The definition of asthma was based on self-reported diagnosis, attacks and medication and the definition of COPD in this study excluded all subjects with a history of asthma as well as participants with non-smoke-related COPD. The reason for this is that we wanted to create two distinct disease groups with no overlap. A separate analysis was undertaken in the group with asthma-COPD overlap. This group had a higher prevalence of reversibility than those with asthma and COPD alone. As in the COPD group reversibility was not associated with any clinical variables, but this might be due to the small number of participants with asthma-COPD overlap in the present investigation. The dose of salbutamol in the range with what is recommended in GINA [1], but lower than what has been recommended in other guidelines [26]. The definitions used for bronchodilator responsiveness was based on BDR testing used in the present analysis [11]. 
The definition of volume-related reversibility in this study may lack precision, as FVC is dependent on both flow and volume. Another limitation is that some of the variables studied, such as IgE sensitisation, was only available in a small subset of those with COPD, and therefore not analysed in this group of participants. Only one BDR test was performed and there is a well-known between-day variability in the classification of the patients as reversible or not [9]. Hence, the clinical usefulness of the test in an individual patient rather than a population is likely to be even lower than suggested here.

We conclude that both flow- and volume-related bronchodilator reversibility were at least as common in participants with smoking-related COPD as those with asthma. This indicates that measures of reversibility are of limited value for distinguishing asthma from COPD. However, in asthma, BDR testing may be a phenotypic marker indicating IgE sensitisation and type 2 inflammation.

Conflict of interest: C. Janson has nothing to disclose. A. Malinovschi has nothing to disclose. A.F.S. Amaral has nothing to disclose. S. Accordini has nothing to disclose. J. Bousquet reports personal fees and other funding from Chiesi, Cipla, Hikma, Menarini, Mundipharma, Mylan, Novartis, Sanofi-Aventis, Takeda, Teva and Uriach, and other funding from Kyomed, outside the submitted work. S.A. Buist has nothing to disclose. G.W. Canonica has nothing to disclose. B. Dahlen has received personal fees from TEVA, Sanofi, GSK and AstraZeneca, outside the submitted work. J. Garcia Aymerich has nothing to disclose. L. Gnatiuc has nothing to disclose. M.L. Kowalski has nothing to disclose. J. Patel has nothing to disclose. W. Tan has nothing to disclose. K. Torén has nothing to disclose. T. Zuberbier has received consultancy fees from Bayer Health Care, FAES, Novartis and Henkel; has received grants/has grants pensing form Novartis and Henkel, and has received lecture fees from AstraZeneca, AbbVie, ALK, Almirall, Astellas, Bayer HealthCare, Bencradm Berlin Chemie, FAES, HAL, Leti, Meda, Menarini, Merck, MSD, Novartis, Pfizer, Sanofi, Stallergenes, Takeda, TEVA, UCB, Henkel, Kryolan and L'Oreal, outside the submitted work. P. Burney has nothing to disclose. D. Jarvis has nothing to disclose.

Support statement: Funding was received from the European Union's Horizon 2020 research and innovation programme (no. 633212S), the Sixth European Union Framework Programme for Research (no. FOODCT_2004-506378), the Medical Research Council (grant number 92091), the Wellcome Trust (no. 085790/Z/08/Z) and the Swedish Heart and Lung Foundation (no. 20170303). For a more complete list of sponsors for the ECRHS and BOLD studies see www.ecrhs.org and www.boldstudy.org. Funding information for this article has been deposited with the Crossref Funder Registry.

\section{References}

1 Global Initiative for Asthma Scientific C. Global Strategy for Asthma Management and Prevention. 2018. Available from: http://ginasthma.org/ Date last accessed December 17, 2018.

2 Albert P, Agusti A, Edwards L, et al. Bronchodilator responsiveness as a phenotypic characteristic of established chronic obstructive pulmonary disease. Thorax 2012; 67: 701-708.

3 Pongracic JA, Krouse RZ, Babineau DC, et al. Distinguishing characteristics of difficult-to-control asthma in inner-city children and adolescents. J Allergy Clin Immunol 2016; 138: 1030-1041.

4 Galant SP, Morphew T, Newcomb RL, et al. The relationship of the bronchodilator response phenotype to poor asthma control in children with normal spirometry. J Pediatr 2011; 158: 953-959.

5 Denlinger LC, Phillips BR, Ramratnam S, et al. Inflammatory and comorbid features of patients with severe asthma and frequent exacerbations. Am J Respir Crit Care Med 2017; 195: 302-313.

6 Durack J, Lynch SV, Nariya S, et al. Features of the bronchial bacterial microbiome associated with atopy, asthma, and responsiveness to inhaled corticosteroid treatment. J Allergy Clin Immunol 2017; 140: 63-75.

7 Hansen EF, Phanareth K, Laursen LC, et al. Reversible and irreversible airflow obstruction as predictor of overall mortality in asthma and chronic obstructive pulmonary disease. Am J Respir Crit Care Med 1999; 159: 1267-1271.

8 Burgel PR, Le Gros V, Decuypère L, et al. Immediate salbutamol responsiveness does not predict long-term benefits of indacaterol in patients with chronic obstructive pulmonary disease. BMC Pulm Med 2017; 17: 25.

9 Calverley PM, Albert P, Walker PP. Bronchodilator reversibility in chronic obstructive pulmonary disease: use and limitations. Lancet Respir Med 2013; 1: 564-573.

10 Quanjer PH, Ruppel GL, Langhammer A, et al. Bronchodilator response in FVC is larger and more relevant than in FEV1 in severe airflow obstruction. Chest 2017; 151: 1088-1098.

11 Tan WC, Vollmer WM, Lamprecht B, et al. Worldwide patterns of bronchodilator responsiveness: results from the Burden of Obstructive Lung Disease study. Thorax 2012; 67: 718-726.

12 Fuertes E, Carsin AE, Antó JM, et al. Leisure-time vigorous physical activity is associated with better lung function: the prospective ECRHS study. Thorax 2018; 73: 376-384.

13 Obaseki D, Potts J, Joos G, et al. The relation of airway obstruction to asthma, chronic rhinosinusitis and age: results from a population survey of adults. Allergy 2014; 69: 1205-1214.

14 Quanjer PH, Stanojevic S, Cole TJ, et al. Multi-ethnic reference values for spirometry for the 3-95-yr age range: the global lung function 2012 equations. Eur Respir J 2012; 40: 1324-1343.

15 Al-Shamkhi N, Alving K, Dahlen SE, et al. Important non-disease-related determinants of exhaled nitric oxide levels in mild asthma - results from the Swedish GA2LEN study. Clin Exp Allergy 2016; 46: 1185-1193.

16 Janson C, Marks G, Buist S, et al. The impact of COPD on health status: findings from the BOLD study. Eur Respir J 2013; 42: 1472-1483.

17 Chhabra SK. Acute bronchodilator response has limited value in differentiating bronchial asthma from COPD. J Asthma 2005; 42: 367-372.

18 Hunter CJ, Brightling CE, Woltmann G, et al. A comparison of the validity of different diagnostic tests in adults with asthma. Chest 2002; 121: 1051-1057. 
19 Herland K, Akselsen J-P, Skjønsberg OH, et al. How representative are clinical study patients with asthma or COPD for a larger "real life" population of patients with obstructive lung disease? Respir Med 2005; 99: 11-19.

20 Travers J, Marsh S, Williams M, et al. External validity of randomised controlled trials in asthma: to whom do the results of the trials apply? Thorax 2007; 62: 219-223.

21 Dweik RA, Boggs PB, Erzurum SC, et al. An official ATS clinical practice guideline: interpretation of exhaled nitric oxide levels (FeNO) for clinical applications. Am J Respir Crit Care Med 2011; 184: 602-615.

22 Vestbo J, Edwards LD, Scanlon PD, et al. Changes in forced expiratory volume in 1 second over time in COPD. N Engl J Med 2011; 365: 1184-1192.

23 Marín JM, Ciudad M, Moya V, et al. Airflow reversibility and long-term outcomes in patients with COPD without comorbidities. Respir Med 2014; 108: 1180-1188.

24 Chou KT, Su KC, Hsiao YH, et al. Post-bronchodilator reversibility of FEV1 and eosinophilic airway inflammation in COPD. Arch Bronconeumol 2017; 53: 547-553.

25 Torén K, Bake B, Olin AC, et al. Measures of bronchodilator response of FEV1, FVC and SVC in a Swedish general population sample aged 50-64 years, the SCAPIS Pilot Study. Int J Chron Obstruct Pulmon Dis 2017; 12: 973-980.

26 Pellegrino R, Viegi G, Brusasco V, et al. Interpretative strategies for lung function tests. Eur Respir J 2005; 26 : 948-968. 